\title{
The Contribution of Mentoring and Action Research to Teachers' Professional Development in the Context of Informal Learning
}

\author{
Evaggelos Anagnou ${ }^{1} \&$ Iosif Fragoulis ${ }^{2}$ \\ ${ }^{1}$ Hellenic Open University, Greece \\ ${ }^{2}$ School of Pedagogical and Technological Education, Hellenic Open University, Greece \\ Correspondence: Iosif Fragoulis, School of Pedagogical and Technological Education, Hellenic Open University, \\ Sokratous 18, Kastelokampos, Rio, zc. 26504, Patra, Greece. Tel: 30-261-091-0066. E-mail:sfaka@otenet.gr
}

Received: December 13, 2013 Accepted: January 13, 2014 Online Published: February 24, 2014

doi:10.5539/res.v6n1p133

URL: http://dx.doi.org/10.5539/res.v6n1p133

\begin{abstract}
This paper focuses on the idea of using informal learning for designing a school-based teachers' professional development (PD) programme. Initially, the issue is discussed in view of educational policy. Following, the theoretical roots and the forms of informal learning are presented. This conversation leads to a suggestion for designing, implementing and evaluating a teachers' PD programme based on informal learning, with specific reference to mentoring and action research.
\end{abstract}

Keywords: informal learning, teachers' professional development, mentoring, action research

\section{Teachers' Training in the Light of Informal Learning}

As long as it considered that the quality of an education system cannot exceed the quality of its teachers, a key element for improving educational and training systems is the teacher. We need not to forget that teacher education and training is one of the 16 quality indicators for school education $(\mathrm{EC}, 2000)$ and one of the 15 quality indicators for lifelong learning (EC, 2002).

Teacher training is a major education policy priority, as it is depicted in policy reports by organizations such as the European Union, Unesco, even the World Bank (EU, 2009; Tiedao, 2002; The World Bank, 2005), as, among others, it: a) is indispensably linked to teachers' professionalization, b) is a component to school improvement, c) affects students' achievement, $\mathrm{d}$ ) is a means of combating school dropout. As stated, "teachers are potentially the most important asset in the notion of a learning society" (Day, 2001).

Policy makers in education acknowledge the necessity for teachers' continuous professional development in the light of lifelong learning, including its informal dimension: "Teachers should be supported in order to continue their professional development. Teachers' lifelong learning could be formal, non-formal and informal." (EC, 2005).

Coffield (2000) concludes, from studies of learning across different contexts, that informal learning is more significant than previously recognized, but tends to be absent from policy making: As he remarks, there is a strong tendency for policy makers, researchers and practitioners to admit readily the importance of informal learning and then proceed to develop policy, theory and practice without further reference to it.

Improving the quality of teaching depends vastly on teachers' training and lifelong learning towards professionalization.Although there is significant amount of scientific literature on teacher learning and professional development in terms of formal training, this is not the case with teachers' informal learning: previous life experiences are rarely, if at all, taken into account in professional development programmes (Shapiro, 2003). Furthermore, there is a tendency for people to not realize and/or underestimate the significance of informal learning experiences they engage into (Eraut, 2004).

The necessity of informal learning, as a crucial means of developing professional expertise, is increasingly acknowledged, as formal education and training represent only a small part of the learning process. It is acknowledged that professionals learn a great deal through informal learning in the workplace. Livingstone's (2000) survey of 1562 Canadian adults' informal learning found that informal learning accounted for "vastly more time than adults are spending in organized education courses". As it is stated, "Whilst the proportion of 
adults not taking part in any type of formal learning activity throughout their lifetime appears to remain consistent at just over a third of the population, we certainly appear to be living in an informal learning society". Therefore, an iceberg is frequently used in literature as illustration of the balance between formal and informal learning, the latter represented by the two-thirds of the iceberg that remains hidden (Livingstone, 1999; Coffield, 2000). According to the U.S. Bureau of Labor Statistics, 70 percent of new learning is acquired through informal learning in the workplace (Benson, 1997).

A crucial reason for not yet taking advantage of teachers' informal learning experiences, is that informal learning is largely invisible, because much of it is either taken for granted or not recognized as learning. Thus, people lack awareness of their own learning; the resultant knowledge is either tacit or regarded as part of a person's general capability, rather than something that has been learned (Eraut, 2004).

Speaking specifically for teachers, their learning opportunities have been described as consisting "mostly of scattered, decontextualized events . . adding up to a hodgepodge of knowledge about teaching and learning that does not lead to a coherent vision or knowledge base to guide practice” (Bobrowsky, Marx, \& Fishman, 2001). This lack of cohesiveness can be a significant roadblock to school improvement.

The problem is that, although informal learning has been explored for some time now in a number of social contexts, unfortunately there has been very little research undertaken in relation to teachers themselves (Smaller, 2005). Furthermore, in spite of the fact that there is a great deal of focus on the need to incorporate and promote informal learning in the workplace, we know little about how it can be supported, encouraged and developed. It is recognized that effective Professional Development design should account for teachers' existing knowledge and beliefs (Hawley \& Valli, 1999). Furthermore, reflection on past experiences can enhance the resultant learning and teachers who explicitly consider their past learning experiences may be better able to identify their true learning needs (Shapiro, 2003).

\section{Theoretical Context for Informal Learning}

The theoretical roots of informal learning can be traced back to Dewey's work (1938), according to which learning must be seen in a lifelong perspective, with the cornerstones of his theory being on experiential learning and reflective thought. Lewin's work on behavior as a function of interaction between a person and their environment (1935), as well on group dynamics and on the action research methodology (1951) has also contributed theoretically.

As Conlon (2004) points out, the term “informal learning" emerged when Knowles (1950), the father of andragogy, published his work Informal Adult Education. Later on (1950), Kolb pointed out that learning is best conceived as a process (and not in terms of outcomes) grounded on experience. He also emphasized that reflection is a critical component of informal learning.

Critical reflection is a key element on Mezirow's theory on transformative learning (1997). According to Mezirow, learning is a process by which we use previous hermeneutic schemata, in order to form a new hermeneutic schema of the meaning of our experiences, so as to use it as a guide for future action. One's lines of action are defined by their frames of reference, which are the structures of assumptions through which we understand our experiences. A frame of is composed of two dimensions: habits of mind and a point of view. Transformation of our frames of reference is achieved through critical reflection on the assumptionsupon which our interpretations, beliefs, and habits of mind orpoints of view are based. The catalyst for transformation is a disorienting dilemma (discrepancy between one's previous hermeneutic schemata and current experience). The educator facilitates learners in becoming aware and critical of their assumptions.

Jarvis offers a synthetic approach on learning. He agrees that learning is both existential and experiential. He, following Freire, believes that education is not neutral, because educational bodies and trainers convey (even subconsciously) part of the dominant ideological and value system they have internalized. He agrees with the vital role of critical reflection, but, drawing on Bourdieu, he believes that "learning is influenced by the social context within which it occurs" (Jarvis, 2009). He, therefore, offers a holistic approach, holding that learning must be seen from both its psychological and sociological perspective, thus "recognising the intersubjectivity of social living and human learning", in the frame of philosophical anthropology (Jarvis, 2009). The practical connotations of his theoretical approach are underlining the importance of planning an adult education project in such a way that: a) the authorities and designers of the project grant part of their power and allow trainees to actively participate in all phases (defining educational targets, designing curriculum, evaluation), b) educational methodology should facilitate learning (empowering method, Socratic method), c) trainers should be trained, in order to develop, additionally to expertise, social skills that will allow them to understand their trainees and reinforce their self acting, thus facilitating their self determination. 


\section{What Is Informal Learning}

There is not a commonly accepted definition of informal learning. Its basic characteristics have been described as follows: "Informal learning is learning resulting from daily life activities, related to work, family or leisure. It is not structured (in terms of learning objectives, learning time or learning support) and typically does not lead to certification. Informal learning may be intentional but in most cases it is non-intentional (or 'incidental')" (European Commission, 2002). Informal learning can also include unlearning old behaviors or practices that have negative consequences or free people to make change (Mariotti, 1999; Cseh, 1998; Magrath, 1997). Informal learning is also described as referring to activities people initiate in work settings that result in the development of their professional knowledge and skills (Cofer, 2000; Lohman, 2000).

According to Livingstone (1999), informal learning can be defined as "any activity involving the pursuit of understanding, knowledge or skill which occurs outside the curricula of educational institutions, or the courses or workshops offered by educational or social agencies". Elaborating on this, Schugurensky (2000) underlines the use of 'learning' and not 'education', mainly due to the absence of prescribed curricula in informal learning. He also emphasizes that "outside the curricula of educational institutions" means that "informal learning can also take place inside formal and non-formal educational institutions".

Watkins and Marsick define incidental learning as a subset of informal learning, with the latter being planned or unplanned but involving conscious awareness that learning is taking place and the former being "...largely unintentional, unexamined, and embedded in people's closely held belief systems" (Watkins \& Marsick, 1992). Lohman holds that, unlike formal learning, informal learning can be planned or unplanned and structured or unstructured (Lohman, 2005).

As it derives from the aforementioned definitions, there is a differentiation in grasping the notion of informal learning, based mainly in two elements: a) the intentionality and consciousness of participants and b) the level of planning and organization of the informal learning procedure.

Schugurensky (2001) provides taxonomy with three forms of informal learning, these being:

a) Self-directed learning “'learning projects' undertaken by individuals (alone or as part of a group) without the assistance of an 'educator' (teacher, instructor, facilitator), but it can include the presence of a 'resource person' who does not regard herself or himself as an educator. It is both intentional and conscious".

b) Incidental learning, referring to "... learning experiences that occur when the learner did not have any previous intention of learning something out of that experience, but after the experience she or he becomes aware that some learning has taken place. Thus, it is unintentional but conscious".

c) Socialization:“....also referred to as tacit learning) refers to the internalization of values, attitudes, behaviors, skills, etc. that occur during everyday life. Not only we have no a priori intention of acquiring them, but we are not aware that we learned something...”.

In order to distinguish explicit informal learning from peoples' everyday perceptions and other tacit learning, Livingstone suggests two criteria: "the retrospective recognition of both a new significant form of knowledge, understanding or skill acquired on one's own initiative and also recognition of the process of acquisition." (Schugurensky, 1999).

Furthermore, Livingstone (2001) distinguishes between (a) informal education and training and (b) self-directed or collective informal learning. The differentiating element between the two is that in (a) teachers or mentors are responsible for instruction "...without sustained reference to an intentionally-organized body of knowledge in more incidental and spontaneous learning situations, such as guiding them in acquiring job skills or in community development activities", while in (b) there is an absence of both teachers and externally-organized curriculum.

\section{Informal Learning in the Workplace: Strategies and Inhibitors}

Informal learning strategies in the workplace include mentoring, action research, coaching, networking, modeling, individual study, listening, observing, reflecting, practicing and refining skills, trial and error, talking and sharing resources with others, getting information and asking questions, searching the Internet and experimenting with new techniques or tools (Marsick \& Watkins, 1990; Eraut, 2004; Lohman, 2005; Marsick, 2009). Informal learning can be used by employees in order to "..obtain help, information or support, learn from alternative viewpoints, gain ability to give greater feedback, consider alternative ways to think and behave (planned or unplanned), reflect on processes to assess learning experience outcomes, and to make choices on where to focus their attention" (Conlon, 2004). 
There are factors that can limit or prevent, and others that can promote participation in informal learning in the workplace. Lohman's survey (2000) pinpointed four environmental inhibitors regarding teachers' involvement in informal workplace learning experiences: lack of time for learning, lack of proximity to learning resources, lack of meaningful rewards for learning, and limited decision-making power in school management. In a subsequent survey (Lohman, 2005), conducted with a sample of 318 public school teachers and HRD professionals, additional inhibitors emerged, namely lack of proximity to colleagues' work areas, an unsupportive organizational culture, the unwillingness of others to participate in informal learning activities and the inaccessibility of subject matter experts. The teachers who participated in the survey also stressed the lack of funds. On the other hand, the same survey highlighted seven personal characteristics that enhance the motivation of both professional groups to engage in informal learning: initiative, self-efficacy, love of learning, interest in the profession, commitment to professional development, a nurturing personality, and an outgoing personality.

\section{Designing an In-School Teachers' Professional Development Programme Based on Informal Learning}

The school unit will decide on how to organize, develop, implement and evaluate the programme. Important issues have to be clarified, such as decision making.A coordinating committee or a coordinator can be designated to have the responsibility for organizing the programme.

\subsection{Design and Development}

The basic parts of design and development of the programme can be as follows:

\section{Prerequisites}

A basic IT infrastructure, as well as a school library will be valuable assets.

\section{Need analysis}

A need analysis is the cornerstone for the success of the programme. People will engage far more willingly if their needs are recognized and addressed properly. A variety of techniques can be used:

a) Focus groups/interviews:Talking to people about how they cope with their daily teaching routine will enable pinpointing needs and will help teachers themselves realize their own needs (as, in many cases, these remain unrecognized and hidden). Questions could involve, e.g.: what resources they use when they come across a problem, what more they would need in order to ameliorate their performance, what poses a problem in their practice, who and where they would turn to when they are meeting a professional challenge or difficulty.

b) Questionnaires: A questionnaire can collect much of the same information as the focus groups/interviews, in a more time efficient manner. However, the lack of the ability to ask follow-up questions or clarify answers can lead to less comprehensive results.

c) Observation: A more time intensive, but potentially more revealing method is to conduct observations of people while they work. The information collected during an analysis will provide a useful account of which informal learning activities work most effectively, which ones don't, and which ones are being underutilised. This will help to inform any improvement plan.

\section{Implementation}

There are several methods to follow, depending on the needs, resources and preferences of those involved. In the following subunit we will focus on two widely used in school environments methods: mentoring and action research.

\section{Monitor and adjust}

Improving the informal learning activity in an organization should be an ongoing process. Some initiatives will be very successful; others will need to be refined over time. Various techniques can be used, depending on the resources of the school unit, the nature of the informal learning activity undertaken, the time availability, the needs of those involved etc. These techniques can be research diaries, observation, questionnaires, interviews, as well as IT based, such as internet forums, social media, e-platforms etc. The coordinator or coordinating team will have the responsibility for gathering and analyzing data, according to which further improvements or amendments will be decided.

\subsection{Mentoring}

Mentoring is considered as an effective method for personnel's professional development and training. It originates from Homer's Odyssey; goddess Athena disguised as Mentor, friend of Odysseus, so that Telemachus would emulate him to learn the skills he would need (Cunningham\&Eberle,1993). As it is supported, "Because 
Mentor served as trusted advisor, teacher, friend, and nurturer, the term came to be associated with those qualities" (Stromei, 2001).

The precise role of a mentor depends on a number of factors such as a) the available time, b) the environment and organization of the working place, c) the mentor's skills and experience, d) the protégées's needs and interests and e) the culture of the organization for developing mentoring procedures.

The typical roles in a mentoring-protégé relationship are generally described as follows: "Mentors demonstrate, explain, model, share and facilitate, while theirprotégées observe, question and explore" (Stromei, 2001).

According to Conway (1995), a mentor acts as: a) Sponsor - who broadens the exposition of protégées, b) Teacher-who creates learning opportunities for protégées, using real or hypothetical circumstances, c) Devil's advocate- where the mentor challenges and confronts the protégées's difficulties, in order to help them towards more effectiveness in their work, d) Coach-where the mentor supports protégées by locating what is important for them to learn, what skills and competences they need to develop and to what extent (Conway, 1995).

Ambrosetti\&Dekkers (2010) in their review of the research literature, suggest the following mentor's roles:

a) Supporter-who assists in mentee's personal and professional development and provides advice and feedback,

b) Role Model-who integrates theory and practice for mentee and assists the mentee by example,

c) Facilitator-who provides guidelines and offers support,

d) Assessor-who makes informed decision on progress,

e) Collaborator-who provides a safe environment for the mentee and shares and reflects with mentees,

f) Friend-who acts as a critical friend, encourages the mentee to try new tasks or challenges and provides advice about weaknesses in a constructive manner,

g) Trainer or Teacher-who provides specific instructions about performing tasks,

h) Protector-who shields the mentee from unpleasant situations,

i) Colleague-who advocates for the mentee in the organisation,

j) Evaluator -who engages in mutual evaluation with mentee and

k) Communicator-referring to sharing of professional knowledge and skills.

Mentoring is therefore very complex and demanding. A mentor's main characteristic is emotional empathy, a crucial factor for the development of a successful mentor-protégé relationship, which is the key to the learning and professional support of protégées (Finlay-Clifford \& Green, 1996).

It offers benefits to mentors, protégées and the organization itself. Specifically (Phillips \& Fragoulis, 2010):

\section{Benefits to Mentor:}

Among others, it:

- Creates opportunities for experienced professionals to strengthen their knowledge base and improve communication skills.

- Enhances the leadership, teaching, and coaching skills of mentors and encourages them to become more reflective practitioners.

- Provides intrinsic satisfaction (makes you feel good) by helping an emerging professional develop to his/her potential.

- Demonstrates professionalism and a commitment to personal and professional development of self and colleagues.

\section{Benefits to Mentee:}

Among others, it:

- Promotes a professional relationship that fosters guidance and support during the mentee's development.

- May increase the self-confidence of a new professional as he/she becomes familiar with a new role, increased responsibilities, or a new organizational culture.

- Challenges mentees to go further, take risks, set new goals, and achieve at higher personal and/or professional standards.

- Reflects the mentee's commitment to personal and professional growth. 


\section{Benefits to Organizations:}

- Contributes to a positive organizational climate and promotes a more clear understanding of professional responsibilities and expectations.

- May increase employee satisfaction and retention by reducing a new employee's sense of isolation.

- May result in improved employee job performance, contribute to faster learning curves, and result in a better trained staff.

- Promotes a positive image of the organization and reflects employee-centred values.

Drawbacks on mentee:

- Neglect of core job

- Negative experiences

- Unrealistic experiences

- Over dependence on the mentoring relationship

- Role conflict between boss and mentor

Drawbacks on mentor:

- Lack of time

- Lack of perceived benefits

- Lack of skills needed for the mentoring role

- Pressure to take on mentoring role

- Resentment of mentees

Drawbacks on organization:

- Lack of organisationalsupport

- Creation of a climate of dependency

- Difficulties in coordinating programs with organisational initiatives

- Costs and resources associated with overseeing and administering programs(Ehrich\& Hansford, 1999).

\subsection{Action Research}

The main characteristics of action research are depicted in the many other names it is known as: participatory research, collaborative inquiry, emancipatory research, action learning and contextural action research. As it is stated, "Put simply, action research is 'learning by doing' - a group of people identify a problem, do something to resolve it, see how successful their efforts were, and if not satisfied, try again" (MacIsaac, 1995). It can be undertaken by the individual teacher, a group of teachers working cooperatively within one school, or a teacher or teachers working alongside a researcher or researchers in a sustained relationship, possibly with other interested parties like advisers, university departments and sponsors on the periphery (Holly \& Whitehead, 1986).

As it is recognized, action research can be used in a variety of areas, for example:

- teaching methods: replacing a traditional method by a discovery method

- learning strategies: adopting an integrated approach to learning in preference to a single-subject style of teaching and learning

- evaluative procedures: improving one's methods of continuous assessment

- attitudes and values: encouraging more positive attitudes to work, or modifying pupils' value systems with regard to some aspect of life

- continuing professional development of teachers: improving teaching skills, developing new methods of learning, increasing powers of analysis, of heightening self-awareness management and control: the gradual introduction of the techniques of behaviour modification

- administration: increasing the efficiency of some aspect of the administrative side of school life (Cohen, Manion, \& Morrison, 2007).

The term action research was first coined by Kurt Lewin in 1946 that codified the action research process into 
four main stages: planning, acting, observing, reviewing and reflecting (Newby, 2010). His model of action research is practically a series of spirals "each of which incorporates a cycle of analysis, reconnaissance, reconceptualization of the problem, planning of the intervention, implementation of the plan and evaluation of the effectiveness of the intervention" (Cohen et al., 2007).

The role of the critical friend (who can be a researcher or an experienced teacher) is valuable to the whole implementation and development of the action project. Usually, diaries are used to inform, monitor and evaluate the action research project.

For action research to be successful, the conditions of collegiality have to be present, for example (Cohen, Manion, \& Morrison, 2007):

- participatory approaches to decision-making

- democratic and consensual decision-making

- $\quad$ shared values, beliefs and goals

- equal rights of participation in discussion

- equal rights to determine policy

- equal voting rights on decisions

- the deployment of subgroups who are accountable to the whole group

- shared responsibility and open accountability

- an extended view of expertise

- judgements and decisions based on the power of the argument rather than the positions power of the advocates

- shared ownership of decisions and practices

Benefits of action research to education

Teachers, students and school have a lot to gain from action research, namely (Gay \& Airasian, 2003; Borgia \& Schuler, 1996; Mills, 2000; Hien, 2009):

- Teachers investigate their own practice in new ways, looking deeper in what they and their students actually do and fail to do.

- Teachers develop a deeper understanding of students, the teacher learning process and their role.

- Teachers are viewed as equal partners in deciding what works best and what needs improvement.

- Teachers are often more committed to action research because they identify the areas they view as problematical and in need of change.

- Action research is an ongoing process and its strategies can be widely applied.

- Professional development and school improvement are core aspects for any teacherwho engages in action research.

- It encourages change in schools.

- It fosters a democratic approach to education.

- It empowers individuals through collaboration on projects.

- It encourages educators to reflect on their practice.

- It promotes a process of testing new ideas.

\section{Disadvantages of action research:}

Three important factors can hinder successful teacher research (Brown, 2002):

a) increased time commitment. As Cochran - Smith and Lytle (1993) pointed out, "Unlike other professions which are organized to support research activities, teaching is a profession in which it is extraordinarily difficult to find enough time to collect data ... reflect, reread, or share with colleagues" (p. 91),

b) lack of distance from the research situation: teacher researchers are not always able to distance themselves from the situation being researched, and therefore are unable to attain an objective viewpoint,

c) conflicts between researching and teaching roles: the purpose of research is to know and understand, while the 
purpose of teaching is "to do the right thing".

\section{Conclusion}

The teaching job is becoming increasingly demanding as regards skills, competencies and knowledge, thus making the necessity for lifelong learning imperative. The school unit needs to become a learning organization for both students and teachers. As it is reported, "Changes in the way of learning, affecting working teachers, are stressing the idea that the responsibility for training falls increasingly on the professionals themselves. Making our schools into areas not only for teaching but in which the teachers learn, is the radical shift needed" (The World Bank, 2005).

Informal learning is a rich, but yet not fully recognized-let alone capitalized upon-source for teacher development. Although present in policy papers, it is mostly absent in actual teachers' professional development programmes. However, it has a lot to offer to both teachers and school organizations and can significantly improve students' learning outcomes and education in general. This becomes conceivable as informal learning activities and projects could lead to improved school climate, closer cooperation between members of the school units, boost of teachers' self-esteem, empowerment of teachers, amelioration of practice, greater commitment and job satisfaction.

\section{References}

Ambrosetti, A., \& Dekkers, J. (2010). The Interconnectedness of the Roles of Mentors and Mentees in Pre-service Teacher Education Mentoring Relationships. Australian Journal of Teacher Education, 35, 42-55. http://dx.doi.org/10.14221/ajte.2010v35n6.3

Benson, G. (1997). Informal training takes off. Training and Development, 51, 93-94.

Bobrowsky, W., Marx, R., \& Fishman, B. (2001). The Empirical Base for Professional Development in Science Education: Moving Beyond Volunteers. Paper presented at NARST, St. Louis Missouri.

Borgia, E. T., \& Schuler, D. (1996). Action research in early chilhood education. USA: University of Illinois, Urbana-Champaign.

Brown, B. L. (2002). Improving Teaching Practices through Action Research. PhD. Dissertation in Educational Leadership and Policy Studies, Virginia: Virginia Polytechnic Institute and State University, Blacksburg.

Cochran-Smith, M., \& Lytle, S. L. (1993). Inside/outside: Teacher-research and knowledge. New York: Teachers College Press.

Cofer, D. A. (2000). Informal workplace learning. Columbus. OH: Center on Education and Training for Employment.

Coffield, F. (2000). Introduction: The structure below the surface: Reassessing the significance of informal learning. In F. Coffield (Ed.), The Necessity of Informal Learning. Bristol: The Policy Press: University of Bristol.

Cohen, L., Manion, L., \& Morrison, K. (2007). Research Methods in Education (6th ed.). Oxon: Routledge.

Conlon, T. J. (2004). A review of informal learning literature, theory and implications for practice in developing global professional competence. Journal of European Industrial Training, 28, 283-295. http://dx.doi.org/10.1108/03090590410527663

Conway, C. (1995). Mentoring managers in organisations. Equal Opportunities International, 14, 1-52. http://dx.doi.org/10.1108/eb010639

Cunningham, J., \& Eberle, T. (1993). Characteristics of the mentoring experience: A qualitative study. Personnel Review, 22, 54-66. http://dx.doi.org/10.1108/00483489310042699

Day, C. (2001). Innovative Teachers: Promoting Lifelong Learning for All. In J. C. D. Aspin, M. Hatton, \& Y. Sawano (Eds.), International Handbook of Lifelong Learning. London: Kluwer.

Dewey, J. (1938). Experience and Education. New York: Collier Books.

Ehrich, L. C., \& Hansford, B. (1999). Mentoring: Pros and cons for HRM. Asia Pacific Journal of Human Resources, 37, 92-107.

Eraut, M. (2004). Informal learning in the workplace. Studies in Continuing Education, 26, $247-273$. http://dx.doi.org/10.1080/158037042000225245.

European Commission. (2000). European report on the quality of school education: Sixteen quality indicators. 
Luxembourg: Office for Official Publications of the European Communities.

European Commission. (2002). European reporton quality indicators of lifelong learning. Fifteen quality indicators, Brussels.

European Commission. (2005). Common European Principles for Teacher Competences and Qualifications. Brussels: European Commission. Directorate-General for Education and Culture.

European Union. (2009). Council conclusions of 12 May 2009 on a strategic framework for European cooperation in education and training ('ET 2020'). Luxembourg: Official Journal of the European Union (2009/C 119/02).

Finlay-Clifford, E., \& Green, V. (1996). The Mentor-Protégé Relationship as a Factor in Preservice Teacher Education: A Review of the Literature. Early Child Development and Care, 125, 73-83.

Gay, L. R., \&Airasian, P. (2003). Education research (2nd ed.). Prentice Hall, New Jersey.

Hawley, W. D., \& Valli, L. (1999). The essentials of professional development: A new consensus. In L. Darling-Hammond, \& G. Sykes (Eds.), Teaching as the learningprofession: Handbook of policy and practice. San Francisco: Jossey-Bass.

Holly, P., \& Whitehead, D. (1986). Action Research in Schools: Getting It into Perspective. Classroom Action Research Network. Cambridge: Institute of Education.

Holly, P., \& Whitehead, D. (1986). Action Research in Schools: Getting It into Perspective. Classroom Action Research Network, Cambridge.

Jarvis, P. (1995). Adult and continuing education: Theory and practice (2nd ed.). New York: Routledge Press.

Jarvis, P. (2009). Learning to be a person in society: Learning to be me. In K. Illeris (Ed.), Contemporary Theories of Learning.Learning theorists ... in their own words. London and New York: RoutledgeTaylor \& Francis Group.

Knowles, M. S. (1950). Informal Adult Education. New York: Association Press.

Kolb, D. (1984). Experiental Learning: Experience as the Source of Learning and Development. New Jersey: Prentice-Hall, Englewood Cliffs.

Lewin, K. (1935). A Dynamic Theory of Personality. New York: McGraw-Hill.

Lewin, K. (1951). Field Theory in Social Sciences. New York: Harper and Row.

Livingstone, D. W. (1999). Exploring the icebergs of adult learning: Findings of the first Canadian survey of informal learning practices. The Canadian Journal for the Study of Adult Education, 13, 49-72.

Lohman, M. C. (2000). Environmental inhibitors to informal learning in the workplace: A case study of public school teachers. Adult Education Quarterly, 50, 83-101. http://dx.doi.org/ 10.1177/07417130022086928

MacIsaac, D. (1995). An Introduction to Action Research. Retrieved from http://www.phy.nau.edu/ danmac /actionrsch.html

Magrath, A. (1997). The importance of unlearning. Across the Board, 2, 39-41.

Mariotti, J. (1999). Change requires learning - and unlearning. Industry Week, 12, 59-60.

Marsick, V. J. (2009). Toward a unifying framework to support informal learning theory, research and practice. Journal of Workplace Learning, 21, 265-275.

Mezirow, J., \& Associates. (2000). Learning as Transformation: Critical Perspectives on a Theory in Progress. San Francisco, CA: Jossey-Bass.

Mezirow, J. (1997). Transformative learning: Theory to practice. In P. Cranton (Ed.), New directions for adult and continuing education: Transformative learning in action: Insights from practice. San Francisco, CA: Jossey-Bass.

Mills, G. (2000). Action research: A guide for teacher researcher. New Jersey: Prentice Hall.

Newby, P. (2010). Research Methods for Education. Essex: Pearson Education Limited.

Phillips, N., \& Fragoulis, I. (2010). Exploring the Beliefs of Primary Education Teachers Regarding the Contribution of Mentoring in Schools. Review of European Studies, 2, 201-213.

Schugurensky, D. (2000). The forms of Informal Learning: Towards a conceptualization of the field. WALL Working Paper (No.19). Centre for the Study of Education and Work, Ontario: Institute for Studies in 
Education of the University of Toronto.

Shapiro, J. K. (2003). Exploring Teachers Informal Learning for Policy on Professional Development. unpublished PhD dissertation. RAND Graduate School, Santa Monica.

Smaller, H. (2005). Teacher informal learning and teacher knowledge: Theory, practice and policy. In N. Bascia, A. Cumming, A. L. Datnow, K. Eithwood, \& D. L. Ivingstone (Eds.), International Handbook of Educational Policy, 13, 543-568.

Stromei, L. K. (2001). Creating Mentoring and Coaching Programmes. In J. J. Philips, \& L. K. Stromei (Eds.), Creating Mentoring and Coaching Programmes (In Action). USA: American Society for Training \& Development.

The World Bank. (2005). Learning to teach in the knowledge society: Final report. Washington DC: The World Bank.

Tiedao, Z. (2002). Reorienating Teachers as Lifelong Learners.A Personal Account for Experiential Learning Programs. In C. Medel-Aňonuevo (Ed.), Integrating Lifelong Learning Perspectives. Hamburgh: Unesco, Institute for Education.

Hien, T. T. T. (2009). Why is action research suitable for education? VNU Journal of Science, Foreign Languages, 25, 97-106.

Watkins, K. E., \& Marsick, V. J. (1992). Towards a Theory of Informal and IncidentalLearning in Organizations. International Journal of Lifelong Learning, 11, 287-300.

\section{Copyrights}

Copyright for this articleis retained by the author(s), with first publication rights granted to the journal.

This is an open-access article distributed under the terms and conditions of the CreativeCommons Attribution license (http://creativecommons.org/licenses/by/3.0/). 